кандидат юридических наук, доцент, доцент кафедры прокурорской деятельности Уральского государственного юридического университета

\section{ЗАЩИТА ОРГАНАМИ ПРОКУРАТУРЫ РФ СОЦИАЛЬНЫХ ПРАВ ГРАЖДАН В СУДАХ ОБЩЕЙ ЮРИСДИКЦИИ: ТЕКУЩЕЕ СОСТОЯНИЕ И ПЕРСПЕКТИВЫ}

\begin{abstract}
Аннотация:
В статье анализируется десятилетняя практика защиты прокурором социальных прав граждан в суде начиная с момента внесения изменений в статью 45 ГПК РФ, предоставивших прокурору возможность защищать социальные права граждан в судах общей юрисдикции. Выявляются проблемы, существующие в этой сфере, предлагаются организационные и правовые механизмы их разрешения. Исследуется актуальный вопрос, связанный с созданием апелляционных и кассационных судов общей юрисдикции. Сформулированы предложения по улучшению эфрективности деятельности прокуратуры на стадии апелляционного и кассационного обжалования судебных актов. Детально проработан вопрос защиты отдельных категорий лии, требующих особого внимания со стороны государства, в частности граждан предпенсионного возраста. Рассматривается зарубежное законодательство, регулирующее деятельность прокуратуры в названной сфрере.
\end{abstract}

Ключевые слова

прокурор, прокуратура, социальные права, гражданский процесс, судебная защита прав, суды общей юрисдикции, прокуратуры зарубежных стран.
PhD in Law, Associate Professor, Prosecutorial Activities Department, Ural State Law University

\section{PROTECTION OF CITIZENS' SOCIAL RIGHTS BY RUSSIAN PROSECUTORS IN COURTS OF GENERAL JURISDICTION: CURRENT STATUS AND PROSPECTS}

Summary:

The research analyzes the ten-year practice of protecting social rights of citizens by the prosecutor since Article 45 of the Civil Procedure Code of the Russian Federation has been amended and it has authorized the prosecutor to protect citizens' social rights in courts of general jurisdiction. The study identifies the relevant problems and presents legal and institutional arrangements to solve them. The establishment of general jurisdiction courts of cassation and appeal is discussed. Proposals are made to improve the effectiveness of the prosecutor's office when reviewing rulings in the courts of cassation and appeal. The research elaborates on the protection of the categories of people in need of special attention from the state, in particular citizens approaching retirement. Besides, the study considers foreign legislation governing the prosecutorial activities in this field.

Keywords: prosecutor, prosecutor's office, social rights, civil procedure, judicial protection of rights, courts of general jurisdiction, prosecutor's offices of other countries.

В период острой фразы экономического кризиса 2008 г. в России был отмечен резкий рост невыплат заработной платы. В связи с этим Генеральной прокуратурой РФ были приняты определенные меры, направленные на сокращение указанной задолженности. В частности, Генеральный прокурор РФ провел ряд встреч в субъектах Российской Федерации с руководителями крупнейших предприятий, у которых имелась задолженность по заработной плате. По результатам рассмотрения фактов невыплаты заработной платы генеральный прокурор внес сотни представлений и предостережений о недопустимости нарушений закона. Завершающим действием Генпрокуратуры РФ в этом направлении стала встреча генерального прокурора Ю. Чайки с президентом РФ Д. Медведевым 12 января 2009 г., по итогам которой президент внес в Государственную думу РФ законопроект, изменяющий статью 45 Гражданского процессуального кодекса РФ (ГПК РФ) в части наделения прокуроров дополнительными полномочиями по защите социальных прав граждан в судах общей юрисдикции [1]. Данный законопроект был подписан президентом РФ 5 апреля 2009 г. и вступил в силу 19 апреля 2009 г. [2].

В соответствии с указанными изменениями прокурор получил право обращения в суд общей юрисдикции по вопросам защиты нарушенных или оспариваемых социальных прав, свобод и законных интересов в сфрере трудовых (служебных) отношений и иных непосредственно связанных с ними отношений; защиты семьи, материнства, отцовства и детства; социальной защиты, включая социальное обеспечение; обеспечения права на жилище в государственном и муниципальном жилищных фондах; охраны здоровья, включая медицинскую помощь; обеспечения права на благоприятную окружающую среду; образования. При этом от прокурора при подаче данных заявлений, в отличие от ранее установленного порядка, не требовалось обосновывать невозможность предъявления иска самими гражданами. 
С момента внесения изменений в ст. 45 ГПК РФ прошло десять лет. В целом по результатам анализа практики применения вышеуказанной нормы последнюю следует оценить как своевременную и необходимую.

Так, из общего количества дел, рассмотренных с участием прокурора в судах общей юрисдикции в 2013 г., дела «обязательной» категории составили 38 \%, по искам прокуроров - 62 \%. При этом удовлетворяемость таких исковых заявлений стабильно высока и достигает 98,5 \% [3, с. 9].

Генеральный прокурор РФ в докладе на расширенном заседании коллегии, посвященной итогам работы органов прокуратуры за 2018 г. и задачам по укреплению законности и правопорядка на 2019 г., состоявшемся 19 марта 2019 г., отметил, что при осуществлении надзора за исполнением законов, соблюдением прав и свобод человека и гражданина в 2018 г. прокурорами выявлено и пресечено более 4 млн нарушений. Значительная их часть касалась обеспечения законности в сфрере оплаты труда. В результате деятельности прокуратуры в данном направлении погашено долгов по заработной плате на сумму 26 млрд р., восстановлены права более 500 тыс. работников. В 2018 г. рассмотрено почти 4,8 млн обращений граждан в связи с нарушением их прав. Более половины жалоб разрешено непосредственно в органах прокуратуры, каждая пятая - удовлетворена. На личном приеме принято более 1 млн человек, в том числе организованы посещение на дому инвалидов, ветеранов и выезд в отдаленные районы [4].

Однако нельзя не отметить и проблемы, с которыми столкнулись прокурорские работники при реализации ст. 45 ГПК РФ в действующей редакции.

Так, суды, несмотря на просьбу гражданина, отказывают прокурору во вступлении в процесс по ч. 3 ст. 45 ГПК РФ в случае, если гражданин ранее самостоятельно направил исковое заявление в суд в защиту своего нарушенного социального права. Также в этом случае прокурор лишен права обратиться с апелляционным (кассационным, надзорным) представлением на решение суда в вышестоящий суд.

В таких случаях прокурору следует неформально подходить к рассмотрению обращения гражданина и использовать другие способы защиты нарушенного права. В частности, можно рассмотреть вопрос об изменении исковых требований и оснований иска. Например, вместо проигранных гражданином требований к администрации района о признании его нуждающимся в улучшении жилищных условий и постановке в очередь на получение жилья как ветерана Великой Отечественной войны предъявить иск об обязании администрации района признать ветерана нуждающимся в улучшении жилищных условий с целью предоставления мер социальной поддержки по обеспечению жильем за счет средств федерального бюджета. Другой вариант - рассмотреть вопрос о возможности подачи апелляционного (кассационного) представления по искам о признании жилого дома самовольной постройкой и его сносе в случаях, когда не заявлялись одновременно требования о выселении и дело было рассмотрено без участия прокурора.

В связи с изложенным представляется целесообразным наделить прокурора правом по собственному усмотрению вступать в процесс по делам о защите социальных прав граждан, а также подавать апелляционные, кассационные и надзорные представления по делам данной категории.

Обратим внимание на недостаточное использование прокурорами частных определений, предусмотренных ст. 226 ГПК РФ, как эффективного механизма восстановления законности. Данный факт отмечен Генеральным прокурором РФ в п. 8 Приказа от 10 июля 2017 г. № 475 «Об обеспечении участия прокуроров в гражданском и административном судопроизводстве», где прокурорам предписано при выявлении в ходе судебного разбирательства нарушений закона обращаться к суду с ходатайством о вынесении частного определения в адрес соответствующей организации или должностного лица, допустившего такие нарушения [5].

Следующая проблема, с которой придется столкнуться в ближайшее время прокурорам при пересмотре судебных актов в апелляционном и кассационном порядке, связана с созданием апелляционных и кассационных судов общей юрисдикции [6]. Соответствующий федеральный конституционный закон вступает в силу с 30 июля 2019 г. К этому времени прокуратуре необходимо завершить все кадровые перестановки, наладить организацию работы по данному направлению, рационально использовать имеющиеся материальные ресурсы и прийти к такому применению норм закона, чтобы обеспечить права граждан - участников судопроизводства на доступ к правосудию в судах апелляционной и кассационной инстанции.

Федеральным законом от 3 октября 2018 г. № 350-Ф3 «О внесении изменений в отдельные законодательные акты Российской Федерации по вопросам назначения и выплаты пенсий» [7] введены дополнительные гарантии социальной поддержки гражданам предпенсионного возраста. В связи с этим на прокуратуру возложены дополнительные обязанности - защищать права граждан предпенсионного возраста, в том числе в судах. Об этом говорится в п. 2.7.2 Приказа Генпрокуратуры РФ № 196 «Об организации прокурорского надзора за соблюдением трудовых прав граждан» от 15 марта 2019 г. (далее - Приказ № 196) [8]. 
При этом законодатель предусмотрел не только гражданско-правовой порядок защиты прав граждан предпенсионного возраста, но и уголовно-правовой. Федеральным законом от 3 октября 2018 г. № 352-Ф3 «О внесении изменения в Уголовный кодекс Российской Федерации» в УК РФ введена статья 144.1, предусматривающая уголовное наказание за необоснованный отказ в приеме на работу или необоснованное увольнение лица, достигшего предпенсионного возраста [9].

Вместе с тем следует высказать критическое отношение к введению данной статьи в Уголовный кодекс РФ, поскольку указанная новелла может привести к заблаговременному увольнению лиц, не достигших предпенсионного возраста, в коммерческих структурах. Считаем, что в этом случае не следует применять репрессивный механизм, наоборот, нужно предоставить предпринимателям льготы по уплате взносов в Пенсионный фонд и Фонд социального страхования с заработной платы лиц, достигших предпенсионного возраста.

Пунктом 3 Приказа № 196 прокурорам предписано обеспечить при наличии оснований подачу в суд исков (заявлений) в защиту трудовых прав граждан, а также привлечение к административной ответственности виновных лиц (в том числе арбитражных управляющих организацийбанкротов, имеющих задолженность по заработной плате); проверять законность судебных актов по делам указанных категорий, инициированным прокурором; контролировать своевременность принятия службой судебных приставов принудительных мер по исполнению требований исполнительных документов, обеспечив реальное исполнение судебных решений, вынесенных по искам (заявлениям) прокуроров, и оперативное поступление информации о сумме погашенной задолженности по заработной плате [10].

Большое внимание со стороны прокуратуры уделяется мониторингу рынка труда, ведется целенаправленная работа по выявлению «серых» и «черных» схем выдачи зарплаты, пресекаются незаконные действия арбитражных управляющих по удовлетворению требований иных кредиторов в ущерб интересам работников, а также необоснованные отказы центров занятости в признании граждан безработными. За год по материалам прокурорских проверок возбуждено свыше 1 тыс. уголовных дел, более 100 тыс. виновных лиц за указанные и иные нарушения привлечены к дисциплинарной и административной ответственности [11].

В анализируемый период прокурорами активно защищались и другие социальные права граждан. Так, в 2018 г. в суды прокурорами заявлено 75 тыс. исков, в том числе об оснащении образовательных учреждений средствами охраны, оборудовании в них медицинских пунктов, создании дополнительных мест в школах и детских садах; почти 24 тыс. исков связаны со сферой ЖКХ, 234 тыс. - с трудовой сфрерой. В 2018 г. стали отдельно учитываться исковые заявления в сфрере законодательства о долевом жилищном строительстве, всего направлено 265 таких исков [12].

Мы разделяем позицию Т.И. Отческой в том, что активная правозащитная деятельность прокуратуры способствует росту доверия к ней российских граждан, которые все чаще обращаются за защитой нарушенных прав к прокурорам [13].

Вместе с тем нельзя не остановиться на проблеме чрезмерной загруженности прокурорских работников. Возрастающее доверие российских граждан к органам прокуратуры приводит к тому, что количество дел, рассмотренных с участием прокурора в судах общей юрисдикции, неизбежно растет. Это повышает нагрузку на прокурорских работников, осуществляющих защиту социальных прав граждан в судах, и, как следствие, снижает качество их подготовки к судебным заседаниям.

Здесь до сих пор остается актуальным мнение М.В. Гадиятовой в отношении принятых к ст. 45 ГПК РФ поправок. Так, с одной стороны, указанные изменения оцениваются положительно, так как относят рассмотрение вопроса о реализации права на подачу иска на усмотрение прокурора, который вправе принять решение исходя из характера правонарушения, загруженности отдельных органов прокуратуры, личных обстоятельств лица, чьи права нарушены, и других фракторов, и практически лишает суд возможности отказа в принятии искового заявления ввиду неуважительности причин, по которым гражданин не может лично поддерживать свои исковые требования. С другой стороны, проблемой может стать кадровое обеспечение прокуратуры. Столь широкие полномочия, предоставленные прокуратуре, значительно увеличат объем работы в первую очередь районных прокуратур. Результатом этого станет «дилемма увеличения штатной численности работников или ограничения числа предъявляемых прокурором исков ввиду загруженности прокуратуры» [14, с. 44-45].

В целях снижения судебной нагрузки на прокуроров по гражданским делам, уменьшения количества так называемых бесспорных дел (где судья проверяет лишь формальные данные) прокурорским работникам следует более активно взаимодействовать с контролирующими органами, в необходимых случаях пользоваться полномочием, установленным п. 4 ст. 22 Федерального закона от 17 января 1992 г. № 2202-1 «О прокуратуре Российской Федерации» [15], - требовать от них незамедлительного проведения проверок и ревизий в поднадзорных объектах и субъектах надзора, использовать иные полномочия в сфере надзора за исполнением закона, за соблюдением прав и свобод человека и гражданина, вносить протесты, представления об устранении нарушений прав и свобод человека и гражданина, предостережения. 
Еще одна проблема связана с определением правового статуса прокурора в гражданском процессе и его полномочий. Поскольку ни ГПК РФ, ни ранее действовавший ГПК РСФСР четко не определили правовой статус прокурора, дискуссии об этом в научной среде ведутся на протяжении уже многих лет. А.А. Мельников [16], А.А. Ференс-Сороцкий [17] предлагают считать прокурора истцом, В.Н. Щеглов [18] и М.С. Шакарян [19] - процессуальным истцом. Автору же близка позиция, изложенная В.И. Торговченковым [20], Н.В. Ченцовым [21] и Н.А. Чечиной [22], которые предлагают придать прокурору самостоятельный процессуальный статус - представителя государства.

Вместе с тем нельзя смешивать правовой статус прокурора в процессе и при осуществлении последним надзорной деятельности. Прокуратура не осуществляет надзор за судом, а действует исключительно в рамках полномочий, предоставленных ГПК РФ, которые по своей сути не являются надзорными. В связи с этим нельзя согласиться с мнением М.Ю. Крутикова, который определяет полномочия прокурора на дачу заключения и обжалование судебных постановлений как процессуальные средства прокурорского надзора в гражданском процессе [23]. Как справедливо указывает Н.А. Васильчикова, к такому ошибочному суждению приводит сопоставление специфических процессуальных полномочий прокурора советского периода и современности в отрыве от изучения правового регулирования деятельности органов прокуратуры [24].

Что касается зарубежного законодательства, регулирующего защиту социальных прав граждан органами прокуратуры, то, например, Гражданский процессуальный кодекс Республики Казахстан в ст. 54 [25] предусматривает подачу прокурором иска для восстановления нарушенных прав и защиты интересов: 1) лиц, которые в силу фризических, психических и иных обстоятельств не могут самостоятельно осуществлять их защиту, 2) неограниченного круга лиц и 3) лиц, общества и государства, если это необходимо для предотвращения необратимых последствий для жизни, здоровья людей либо безопасности Республики Казахстан. Гражданский процессуальный кодекс Республики Беларусь в ст. 81, 82 [26] предоставляет прокурору право обратиться в суд с заявлением о возбуждении гражданского дела в защиту любых нарушенных прав граждан, а также юридических лиц. При этом прокурор не обязан обосновывать необходимость подачи такого иска.

По словам Ю. Чайки, в странах - членах Совета Европы более 30 прокуратур обладают полномочиями вне уголовно-правовой сферы, включая функцию участия прокурора в гражданском судопроизводстве с различным объемом полномочий [27].

Так, во Франции прокурор наделен широкими полномочиями по участию в гражданском судопроизводстве. По определенным категориям дел участие прокурора в гражданском процессе является обязательным: по защите прав несовершеннолетних, когда возникает угроза их здоровью, образованию и безопасности; по вопросам гражданства; по защите интересов лиц с психическими недостатками, защите прав и интересов инвалидов [28]. Прокуроры во Франции наделены правом обжалования судебных актов вплоть до высших инстанций. В частности, Генеральный прокурор при Кассационном суде Франции в целях наиболее полного удовлетворения публичного и общественного интереса наделен правом кассационного обжалования [29].

В отличие от Франции в Германии вмешательство прокуроров в некриминальные сферы права ограничивается лишь представлением в суде интересов гражданина, признанного умершим [30].

Таким образом, по результатам проведенного исследования и анализа деятельности прокуроров за последнее десятилетие можно обозначить направления развития органов прокуратуры в РФ. С целью повышения эфффективности их работы по защите социальных прав граждан в судах общей юрисдикции, а также с учетом создания территориально обособленных апелляционных и кассационных округов судов общей юрисдикции следует и далее совершенствовать гражданское процессуальное законодательство, активно внедрять в прокуратуре сервисы электронного документооборота, создать единую государственную автоматизированную систему правовой статистики (ГАС ПС), единую защищенную внутреннюю сеть передачи данных, внедрить современные методики обучения прокуроров, в том числе информационным технологиям.

\section{Ссылки:}

1. Рабочая встреча с Генеральным прокурором Юрием Чайкой [Электронный ресурс] // Президент России. 2009. 12 янв. URL: http://www.kremlin.ru/events/president/news/2825 (дата обращения: 15.03.2019).

2. О внесении изменений в статьи 45 и 131 Гражданского процессуального кодекса Российской Федерации : федер. закон от 5 апр. 2009 г. № 43-Ф3 // Собрание законодательства РФ. 2009. № 14.6 апр. Ст. 1578.

3. Квитко Н.И. Защита прокурором прав граждан в гражданском процессе // Законность. 2014. № 11 (961). С. 9-12.

4. Доклад на заседании Совета Федерации Федерального Собрания Российской Федерации [Электронный ресурс] // Генеральная прокуратура РФ : офиц. сайт. 2018. 18 aпр. URL: https://genproc.gov.ru/smi/interview_and_appearences/appearences/1367434/ (дата обращения: 15.03.2019).

5. Об обеспечении участия прокуроров в гражданском и административном судопроизводстве : приказ Генерального прокурора РФ от 10 июля 2017 г. № 475 // Законность. 2017. № 10 (996). С. 63-67. 
6. О внесении изменений в федеральный конституционный закон «О судебной системе Российской Федерации» и отдельные федеральные конституционные законы в связи с созданием кассационных судов общей юрисдикции и апелляционных судов общей юрисдикции : федер. конституц. закон от 29 июля 2018 г. № 1-ФКЗ // Российская газета. 2018. № 165. 31 июля.

7. О внесении изменений в отдельные законодательные акты Российской Федерации по вопросам назначения и выплаты пенсий : федер. закон от 3 окт. 2018 г. № 350-Ф3 // Российская газета. 2018. № 223. 5 окт.

8. Об организации прокурорского надзора за соблюдением трудовых прав граждан [Электронный ресурс] : приказ Генпрокуратуры РФ от 15 марта 2019 г. № 196. URL: https://genproc.gov.ru/upload/orders/196gp.pdf (дата обращения: 20.03.2019).

9. О внесении изменения в Уголовный кодекс Российской Федерации : федер. закон от 3 окт. 2018 г. № 352-Ф3 // Российская газета. 2018. № 223. 5 окт.

10. Об организации прокурорского надзора за соблюдением трудовых прав граждан.

11. Состоялось расширенное заседание коллегии, посвященное итогам работы органов прокуратуры за 2018 г. и задачам по укреплению законности и правопорядка на 2019 г. [Электронный ресурс] // Генеральная прокуратура РФ. 2019. 19 марта. URL: https://genproc.gov.ru/smi/news/genproc/news-1573512/ (дата обращения: 20.03.2019).

12. Статистические данные об основных показателях деятельности органов прокуратуры Российской Федерации за январь - декабрь 2018 г. [Электронный ресурс] // Там же. 12 февр. URL: https://genproc.gov.ru/stat/data/1548464/ (дата обращения: 20.03.2019).

13. Отческая Т.И. Обеспечение прокуратурой и судами свободы экономической деятельности // Законы России: опыт, анализ, практика. 2018. № 6. С. 70-74.

14. Гадиятова М.В. Защита прокурором частных интересов в гражданском судопроизводстве // Законность. 2010. № 11. C. 44-46.

15. О прокуратуре Российской Федерации : федер. закон от 17 янв. 1992 г. № 2202-1 // Российская газета. 1992 . № 39. 18 февр.

16. Защита прав личности в социалистическом гражданском процессе / под общ. ред. А.А. Мельникова. М., 1986. 310 с.

17. Ференс-Сороцкий А.А. Прокурор в гражданском судопроизводстве // Известия высших учебных заведений. Правоведение. 1992. № 4. С. 91-95.

18. Щеглов В.Н. Субъекты судебного гражданского процесса. Томск, 1979. 129 с.

19. Шакарян М.С. Субъекты советского гражданского процессуального права. М., 1970. 214 с.

20. Торговченков В.И. Институт участия прокурора в гражданском судопроизводстве // Законность. 2015. № 7 (969). С. $45-49$.

21. Ченцов Н.В. Проблемы защиты государственных интересов в гражданском судопроизводстве. Томск, 1989. 185 с.

22. Чечина Н.А. Основные направления развития науки советского гражданского процессуального права. Л., 1987. 104 с.

23. Крутиков М.Ю. Гражданско-процессуальный статус прокурора // Современное право. 2007. № 5. С. 67-70.

24. Васильчикова Н.А. Полномочия прокурора в гражданском судопроизводстве // Современное право. 2018. № 6. С. 97-101.

25. Гражданский процессуальный кодекс Республики Казахстан от 31 окт. 2015 г. № 377-V ЗРК [Электронный ресурс] : с изм. и доп. по состоянию на 24 апр. 2019 г. // Параграфр: информационные системы. URL: https://online.zakon.kz/document/?doc id=34329053\#pos=2;-155 (дата обращения: 01.05.2019).

26. Гражданский процессуальный кодекс Республики Беларусь от 11 янв. 1999 г. № 238-3 [Электронный ресурс] // Кодексы Республики Беларусь. URL: http://kodeksy.by/grazhdanskiy-processualnyy-kodeks (дата обращения: 20.03.2019).

27. Интервью «Российской газете» «Правозащита Юрия Чайки» [Электронный ресурс] // Генеральная прокуратура РФ. 2008. 16 июля. URL: https://genproc.gov.ru/smi/interview_and_appearences/interview/65713/ (дата обращения: 01.05.2019).

28. Gilliéron G. Public Prosecutors in the United States and Europe. A Comparative Analysis with Special Focus on Switzerland, France, and Germany. Brig, 2014. 387 p. https://doi.org/10.1007/978-3-319-04504-7.

29. Ковтков Д.И. Кассационное производство в гражданском процессе Российской Федерации и некоторых зарубежных стран. М., 2018. 187 с.

30. Хавронюк M.I. Прокуратура по-німецьки: закону немає, а ордонунг $\epsilon$ [Электронный ресурс] // Законопроект. URL: http://www.zakonoproekt.org.ua/prokuratura-po-nimetsjki-zakonu-nemaje-a-ordnungh-je_.aspx (дата обращения: 20.03.2019).

\section{References:}

Chechina, NA 1987, The Main Directions of Development of Science of the Soviet Civil Procedural Law, Leningrad, 104 p., (in Russian).

Chentsov, NV 1989, Problems of Protection of State Interests in Civil Proceedings, Tomsk, 185 p., (in Russian).

Ferens-Sorotsky, AA 1992, 'Prosecutor in Civil Proceedings', Izvestiya vysshikh uchebnykh zavedeniy. Pravovedeniye, no. 4, pp. 91-95, (in Russian)

Gadiyatova, MV 2010, 'Protection by the Prosecutor of Private Interests in Civil Proceedings', Zakonnost', no. 11, pp. 44-46,

(in Russian).

Gilliéron, G 2014, Public Prosecutors in the United States and Europe. A Comparative Analysis with Special Focus on Switzerland, France, and Germany, Brig, 387 p., https://doi.org/10.1007/978-3-319-04504-7.

Khavronyuk, MI 2019, 'The Prosecutor's Office is in German: There Is No Law, and the Ordonung Is', Zakonoproekt, viewed

20 March 2019, <http://www.zakonoproekt.org.ua/prokuratura-po-nimetsjki-zakonu-nemaje-a-ordnungh-je .aspx>, (in Ukrainian). Kovtkov, DI 2018, Cassation Proceedings in Civil Proceedings of the Russian Federation and Some Foreign Countries, Moscow, 187 p., (in Russian).

Krutikov, MYu 2007, 'The Civil Procedure Status of the Prosecutor', Sovremennoye pravo, no. 5, pp. 67-70, (in Russian). Kvitko, NI 2014, 'Protection by the Public Prosecutor of the Citizens Rights in Civil Proceedings', Zakonnost', no. 11 (961), pp. 9-12, (in Russian).

Melnikov, AA (ed.) 1986, Protection of the Rights of the Individual in the Socialist Civil Process, Moscow, 310 p., (in Russian). Otcheskaya, TI 2018, 'Ensuring the Prosecutor's Office and the Courts Freedom of Economic Activity', Zakony Rossii: opyt, analiz, praktika, no. 6, pp. 70-74, (in Russian).

Scheglov, VN 1979, Subjects of Judicial Civil Procedure, Tomsk, 129 p., (in Russian)

Shakaryan, MS 1970, Subjects of the Soviet Civil Procedural Law, Moscow, 214 p., (in Russian).

Torgovchenkov, VI 2015, 'Institute of the Participation of the Prosecutor in Civil Proceedings', Zakonnost', no. 7 (969), pp. 4549, (in Russian).

Vasilchikova, NA 2018, 'Powers of the Prosecutor in Civil Proceedings', Sovremennoye pravo, no. 6, pp. 97-101, (in Russian) 